\title{
An open source LoRa based vehicle tracking system
}

\author{
Norhafizah Ramli, Muhammad Mun'im Zabidi, Anuar Ahmad, Ivin Amri Musliman \\ Universiti Teknologi Malaysia, Malaysia
}

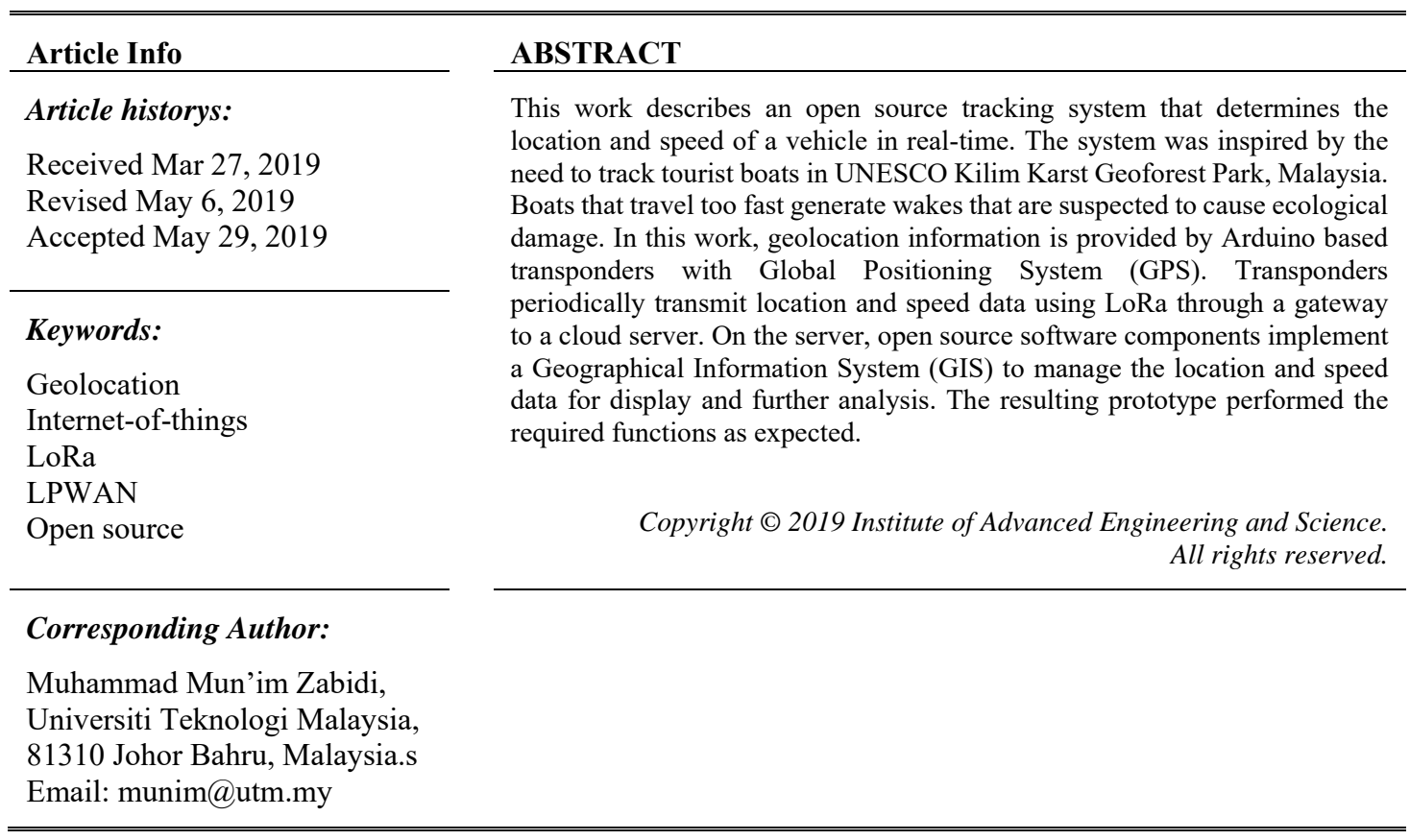

\section{INTRODUCTION}

Over the last few years, the Internet of Things (IoT) has received more attention in terms of research and industrial applications [1]. In the IoT paradigm, many objects that surround us are connected with cloudbased computing. IoT is used in a plethora of applications such as agriculture [2], smart cities [3] and healthcare [4]. Vehicle fleet tracking is one IoT application where fleet assets can be tracked in real-time. It provides the ability to instantaneously detect infractions such as route deviations and speeding violations and enables the off-line analysis of traffic patterns and driver behavior.

This project is part of a larger project on the sustainability of the UNESCO Kilim Karst Geoforest Park, Malaysia [5]. The mangrove trees in the park were dying from erosion and the UNESCO status is in danger from being withdrawn if no action was taken. The prime suspect for the erosion was the wake from tourist boats that travel too fast. A boat tracking system would be able to establish the correlation between boat speed and mangrove erosion. The tracking system described here works not only on boats but should work on other vehicle types as well.

Numerous studies on long-range asset tracking have been published. Lee et al developed a smartphone-based user interface (UI) for a vehicle tracker using GPS as sensor and GSM/GPRS to transmit data [6]. Verna et al devised a mobile robot tracking using GPS and GSM [7]. Kamble implemented a bus tracking system using RFID as a sensor [8].

The wireless interface to be selected depends on the transmission range and data rate. For boat tracking, a range of $10 \mathrm{~km}$ and a location report per minute are sufficient. Several IoT communication technologies are listed in Table 1 [9-11]. Among them, LoRa, NB-IoT and Sigfox form a new group called low power wide area network (LPWAN). LPWAN is gaining popularity in the IoT community due to low power, long range and low-cost characteristics. We eliminated GSM, UMTS, LTE, NB-IoT and SigFox due to the licensing and/or subscription requirement. For our purposes, LoRa provides the best tradeoff in terms of cost, transmission range, and reporting rate. 
Table 1. Communication technologies in IoT [9-11].

\begin{tabular}{cccc}
\hline Technology & Transmission Range & Peak Data rate & Licensing/Subscription \\
\hline RFID & $3 \mathrm{~m}$ & $424 \mathrm{kbps}$ & No \\
Bluetooth & $10 \mathrm{~m}$ & $1 \mathrm{Mbps}$ & No \\
ZigBee & $10 \mathrm{~m}$ & $256 \mathrm{kbps}$ & No \\
WiFi & $100 \mathrm{~m}$ & $320 \mathrm{Mbps}$ & No \\
NB-IoT & $10 \mathrm{~km}$ & $204.8 \mathrm{kbps}$ & Yes \\
LoRa & $20 \mathrm{~km}$ & $50 \mathrm{kbps}$ & No \\
UMTS/GSM & $30 \mathrm{~km}$ & $9.6 \mathrm{Kbps}$ & Yes \\
SigFox & $40 \mathrm{~km}$ & $100 \mathrm{bps}$ & Yes \\
\hline
\end{tabular}

LoRa is used in several related research. Baharudin and Yan performed data integrity tests on LoRa sending GPS data [12]. San-Um et al described a similar system specifically for tracking troop movement [13]. Zinas et al devised a cattle tracking system in Italy on open source architecture [14]. Li et al performed experiments on LoRa during the Brazil Olympics sailing venue [15]. Most tracking applications use GPS as it provides an easy-to-use mechanism and a practical way of obtaining location information. The accuracy of GPS position can be estimated up to $\pm 6 \mathrm{~cm}$ when combined with a source of differential correction (e.g. Differential GPS (DGPS)) [16]. This kind of accuracy combined with the availability of the GPS satellite network would seem to be the ideal for outdoor localization application such as vehicle tracking. However, signals from the GPS satellites can be blocked by solid objects such as buildings and trees and in some cases, position estimates are confounded by multipath; GPS signals that bounce off solid objects. Hence, for vehicle tracking operation in urban environments, GPS alone does not provide the level of reliability. On the other hand, multipath is not a consideration in boat tracking applications, therefore, DGPS is not necessary.

\section{SYSTEM DESIGN}

The model of our architecture is based on the LoRa reference. We started with assembling the hardware and software components defined by the architecture. From the experimental setup, we verified the data from the transponder with the actual data stored in the server and graphics display.

The system architecture as shown Figure 1 consists of three main hardware components: the transponder, the gateway, and the server. The transponder reads GPS signals from satellites and transmits a packet every second. The gateway receives packets from transponders and relays the packet to the server. Figure 2 shows the UML system sequence diagram which describes the system operation and data flow. The main actor is the transponder which sends a GPS data packet every minute to the gateway. The gateway then relays the packet through an Internet connection to the server where it is saved as SQL records. A client may view the data records in real-time or delayed either in tabular or graphical form.

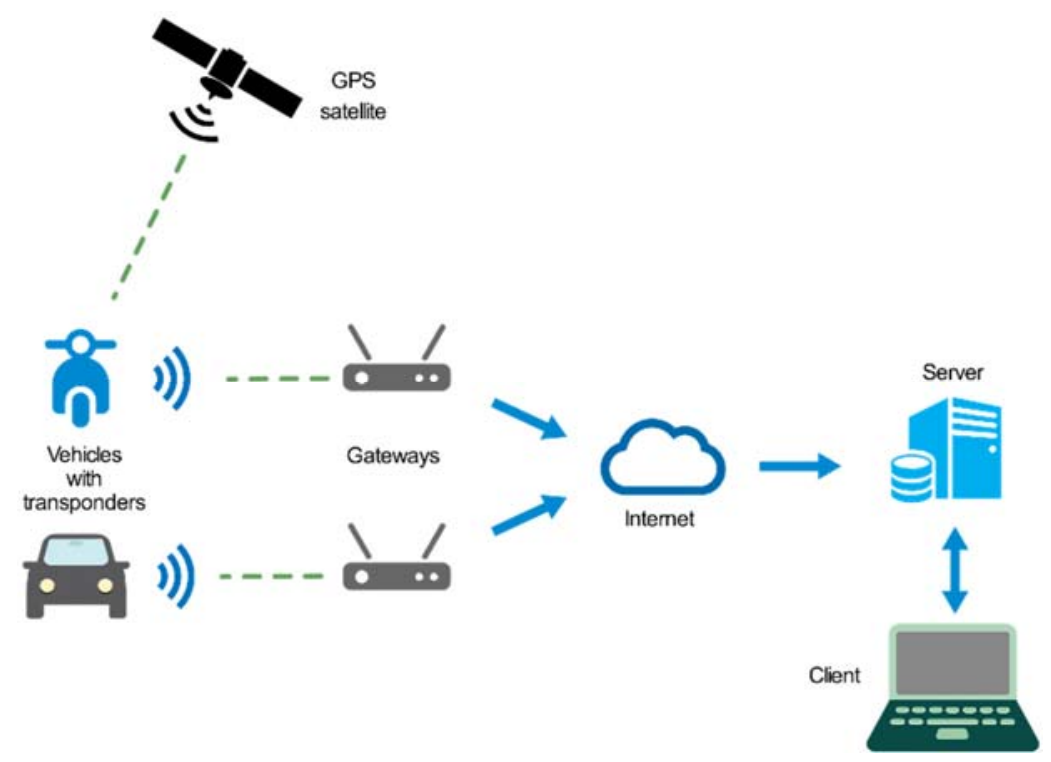

Figure 1. The architecture of vehicle tracking system. 


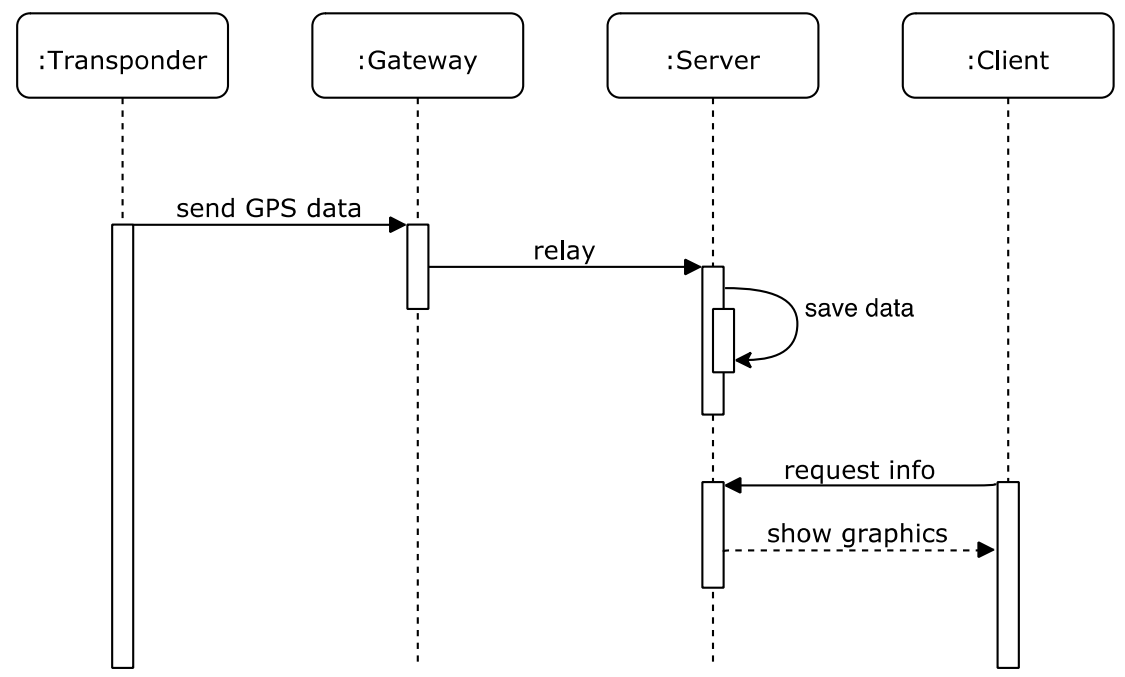

Figure 2. UML system sequence diagram for system operation.

We built our own transponder prototypes to explore the various aspects of the design. Eventually, we wish to fabricate an optimized version of the transponder. Thereby, we looked into the potential of each platform for miniaturization when deciding on the base platform. The main components of the transponder are the GPS receiver, the LoRa transmitter and the processor board. Raspberry Pi [17], Beaglebone [18] and Arduino [19] families were shortlisted as all three have sufficient performance required for the task and we are comfortable with using any of them. The main design metrics are listed in Table 2, in order of importance.

The first metric is rapid prototyping: Arduino is the clear choice due to the ease of component sourcing and a simpler development process. The second metric is power consumption. Based on an 8-bit AVR processor compared 32-bit ARM, Arduino uses significantly less power and long term operation on battery power is definitely possible. The third metric is reliability. The Raspberry Pi and Beaglebone both have software higher reliability by virtue of an operating system. The disadvantage of Arduino can be mitigated by keeping the onboard code as simple as possible. Hardware-wise, the Beaglebone is more desirable than Raspberry Pi due to the use of soldered eMMC chips for operating systems storage instead of removable microSD cards. The fourth metric is system openness. Openness impacts potential customizations, and some parts of the Raspberry $\mathrm{Pi}$ is closed source. The last metric is cost. The cost of Arduino based solution is lowest, although it should be noted the cost GPS sensor and LoRa transmitter forms a significant fraction of the transponder cost. After considering the tradeoffs, we decided to use the Arduino as the base platform.

Table 2. Processor boards for transponder.

\begin{tabular}{cccc}
\hline Metric & Raspberry Pi & Beaglebone & Arduino \\
\hline Rapid prototyping & Moderate & Low & High \\
Power consumption & High & High & Low \\
Reliability & Very High & Highest & High \\
Openness & Partial & Yes & Yes \\
Cost & High & High & Low \\
\hline
\end{tabular}

We used two transponders for this work is shown in Figure 3. The first version, on the left, is a Dragino GPS/LoRa shield was stacked on top of the bare Arduino Uno board. The version transponder, on the right, used an integrated Arduino/Lora model to which we attached a different GPS sensor. The second version has an LCD display used for debugging, a LiPo battery with a built-in battery charger.

The LoRa gateway is a Dragino LG01 unit, shown in Figure 4. It receives and transmits LoRa wireless data at a frequency of $868 \mathrm{MHz}$. Transponder data is transferred to a server located across the Internet connection via $\mathrm{LAN}, \mathrm{WiFi}, 3 \mathrm{G}$ or $4 \mathrm{G}$. The gateway runs the open-source OpenWrt operating system and future customizations are possible. It is an auto-provisioning device with a built-in web server for configuration by Web GUI, or alternatively through a debugging link. 


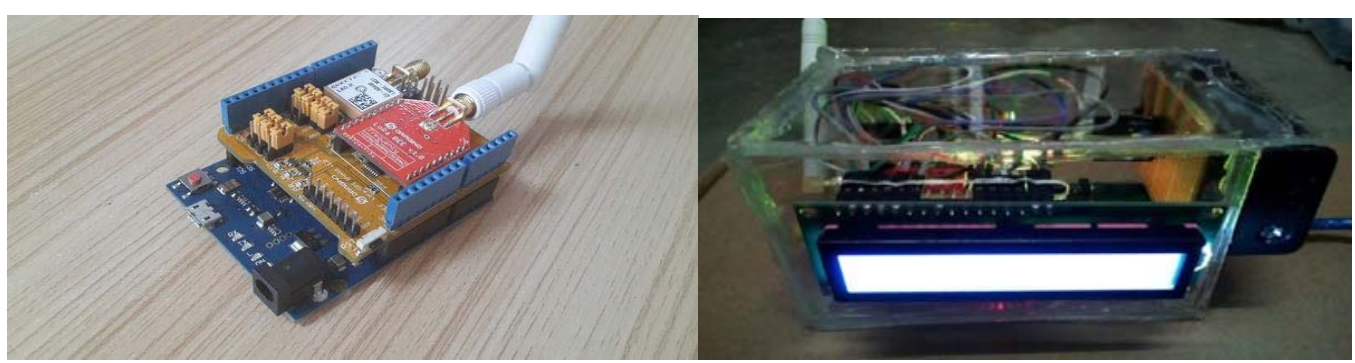

(a)

(b)

Figure 3. Transponder assembly: (a) Version 1, and (b) Version 2.

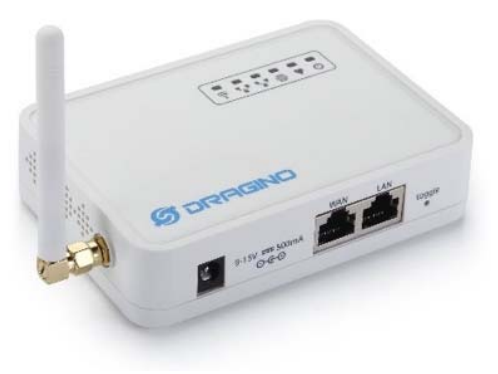

Figure 4. Dragino LG01 gateway.

The software suite on the server is based on the open source LAMP (Linux, Apache, MySQL, PHP) philosophy. While we mainly used PHP, we used some Perl and Ruby scripts to optimize coding productivity. We opted to use MariaDB for database management. MariaDB is a community-developed fork of MySQL over concerns of its openness. Figure 5 shows the server architecture showing the main PHP scripts.

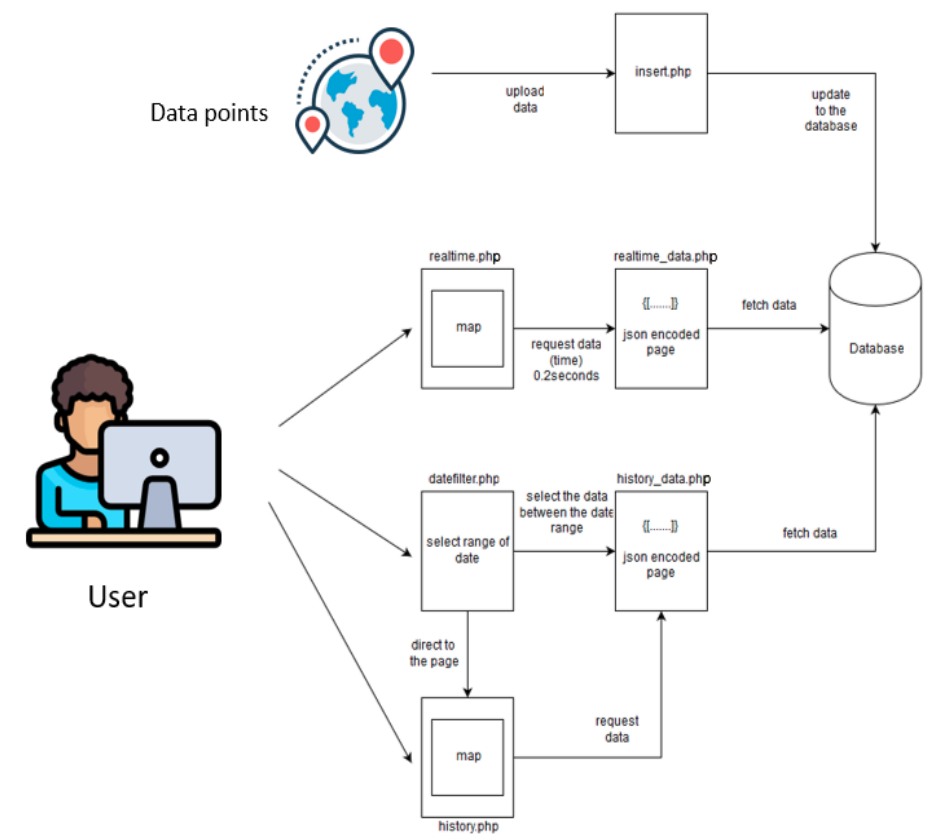

Figure 5. Web server software architecture. 


\section{RESULTS}

This section presents the results of experiments to verify system operation as suggested in Figure 2 . The transponder was tested to simulate the original application of tracking boats in open waters. There, location data is available continuously from satellites. To test the transponder operation, satellite data is sampled every second and immediately transferred to the LoRa gateway. Using the serial debugging monitor, a snapshot of the data can be viewed in Arduino IDE as shown in Figure 6. Here, the GPS derived data is Longitude 103.647870 and Latitude 1.555085. These values were later compared with the values at the gateway.

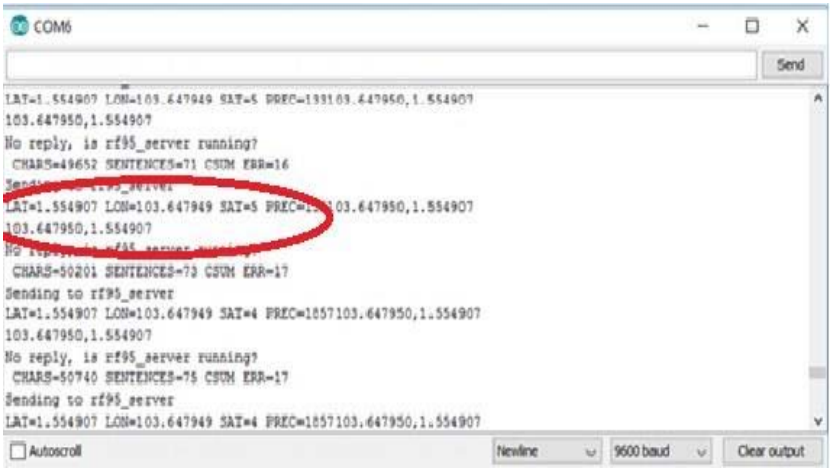

Figure 6. Transponder data snapshot.

The basic function of the gateway is to relay location data to the server. In case of connectivity interruptions, however, the gateway can temporarily store data in its USB flash drive until connectivity is restored. We used this facility to verify the data received from the transponder. Figure 7 shows the arrangement of data namely Longitude, Latitude and Time in CSV format. The data can be read by any text editor or Microsoft Excel. The time in this file is the timestamp of the packet arriving in the gateway.

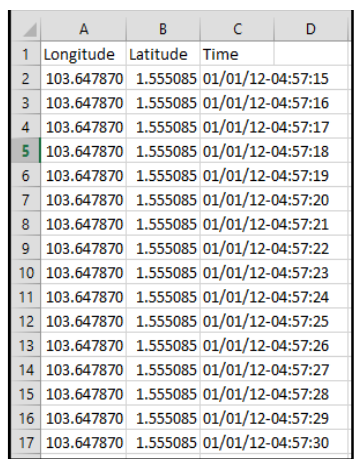

Figure 7. Snapshot of data stored in USB Flash.

When geolocation data arrives from the gateway, it is stored by the server in a table containing Longitude, Latitude and Time. Figure 8 shows the snapshot of data stored in the server.

\begin{tabular}{|lll|}
\hline Longtitude & Latitude & Times \\
1.24 & 1.24 & $2018-04-0323: 53: 22$ \\
1.24 & 1.24 & $2018-04-0323: 53: 24$ \\
1.2468 & 1.286 & $2018-04-03 \quad 23: 53: 31$ \\
1.2468 & 1.286 & $2018-04-0401: 10: 27$ \\
103.647870 & 1.555085 & $2018-05-07 \quad 20: 48: 04$ \\
103.647870 & 1.555085 & $2018-05-07 \quad 20: 48: 04$ \\
103.647870 & 1.555085 & $2018-05-07 \quad 20: 48: 07$ \\
103.647870 & 1.555085 & $2018-05-07 \quad 20: 48: 07$ \\
\hline
\end{tabular}

Figure 8. Snapshot of database table. 
After verifying the operation of the individual components of the architecture, the location data must be validated. A series of geolocations packets were collected by moving around in the Skudai campus of Universiti Teknologi Malaysia. Next, we used the open source KMLCSV software to verify the location. The software was able to read longitude and latitude and then display in on the map as a red mark. Other details collected are shown as a comment, such as time and RSSI. The location indicated by KMLCSV pinpointed the transponder accurately as shown in Figure 9.

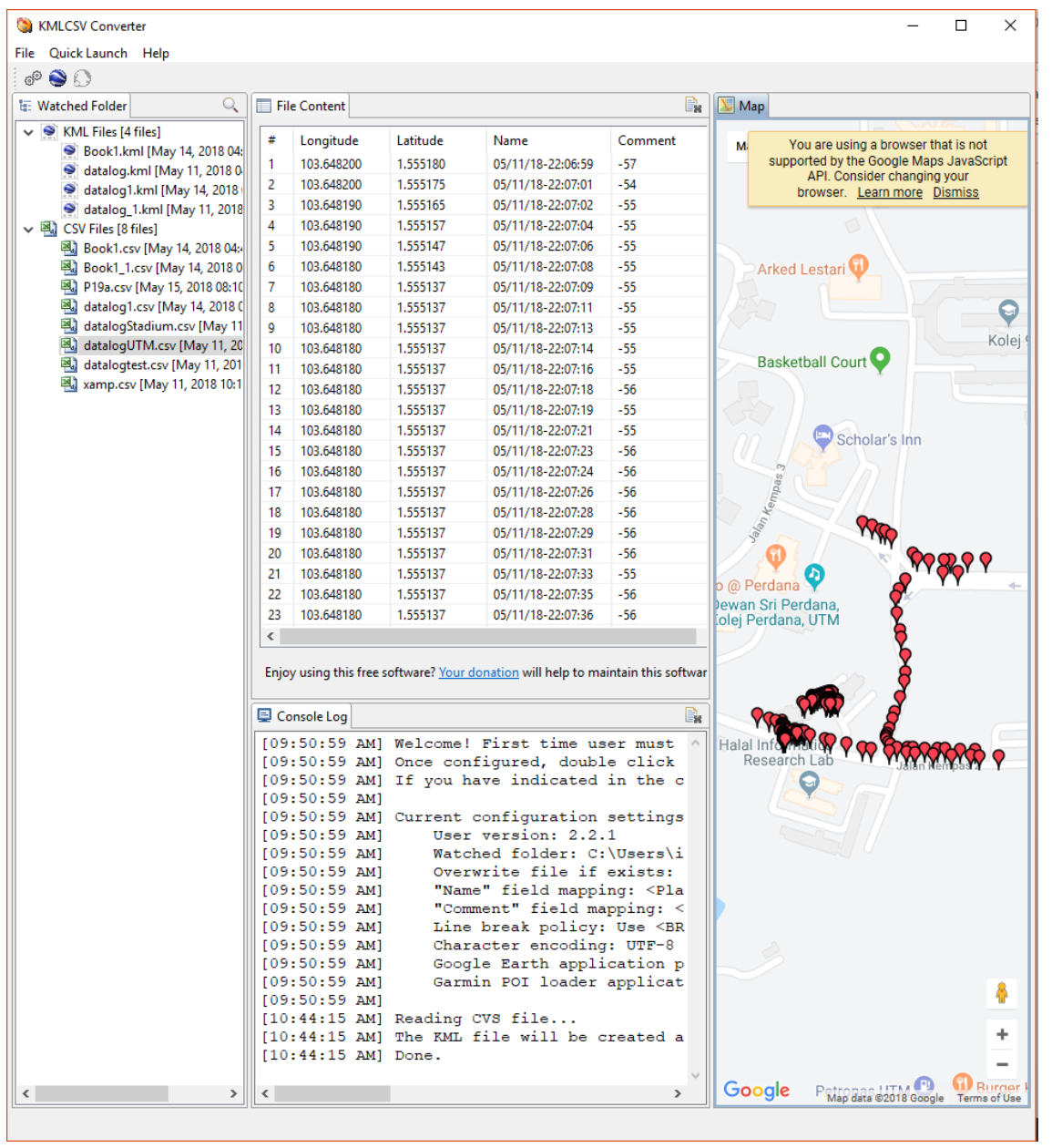

Figure 9. KMLCSV software screenshot.

LoRa claims its urban and rural ranges are $2 \mathrm{~km}$ and $20 \mathrm{~km}$ respectively. We use the KMLCSV software to analyze the gateway coverage and verify these claims. In Figure 10, the gateway located in the center of the circle. The average limit of the gateway is at 400 -meter radius indicated by the circle in the map. No signal was detected in the shaded area as the radio signal was blocked by a building, therefore, a shaded area. This is far below the expected range of LoRa. We conclude that in order for a vehicle tracking system to work effectively, sources of signal attenuation must be overcome. Some methods include the use of a higher quality antenna and improving the height and placement of the antenna.

Another set of scripts on the server allows the user to review historical data and perform basic analysis. After entering the start and end times, data is fetched from the database and presented on the web browser using JSON. The data is displayed in text form in Figure 11. Next, the Mapbox API and Leafleat.JS allow the user to view vehicle tracks with color-coded with speed. Figure 12 shows tracks of boats traveling in Langkawi Geoforest Park. Note however that these tracks were obtained before the start of this project using GPS tracking mobile apps.

Indo. J. Elec. Eng. \& Inf, Vol.7, No. 2, June 2019: 221 - 228 


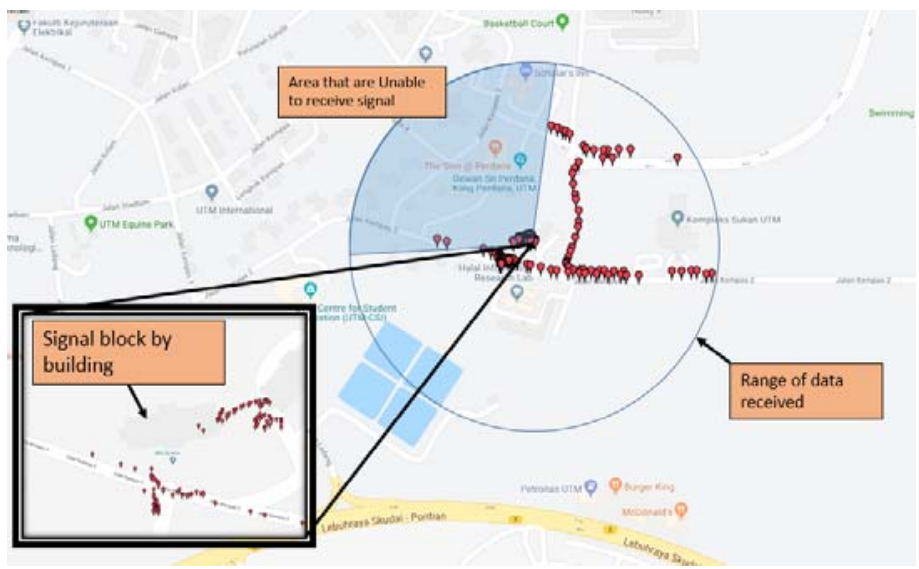

Figure 10: Gateway Coverage

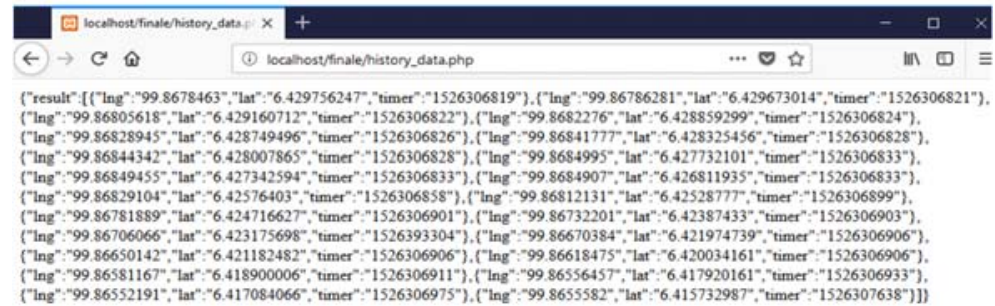

Figure 11. Fetching of historical data from the database.

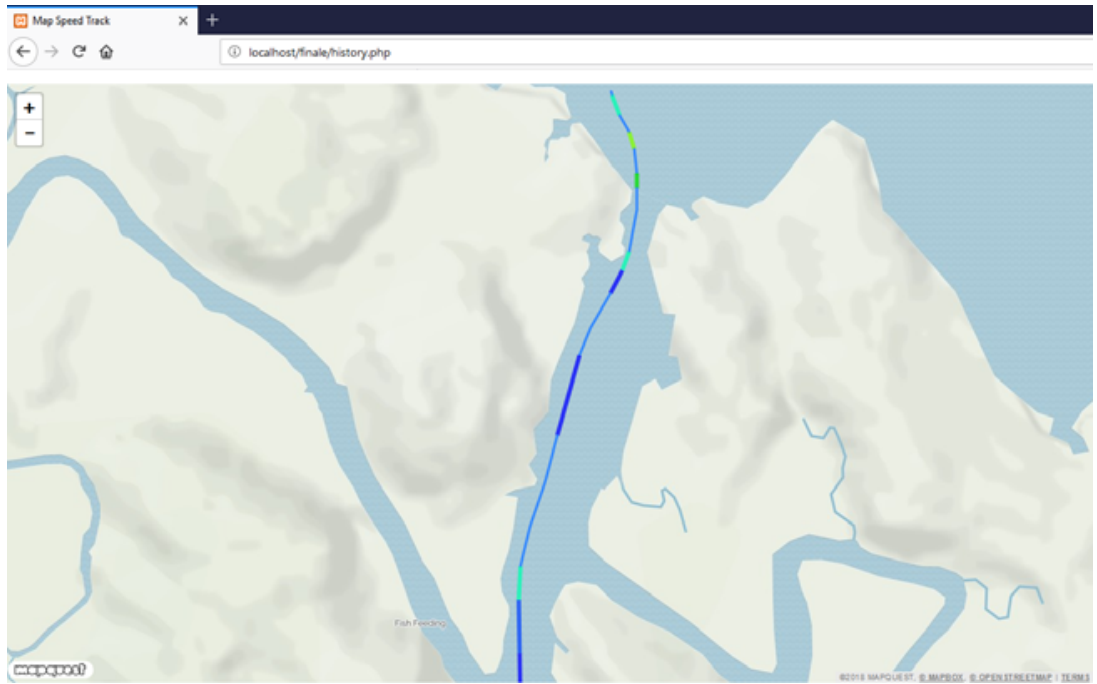

Figure 12. The history data collected in Langkawi is visualized.

Our system is comparable to several similar LoRa based vehicle trackers. Baharudin and Yan [12] studied on the Received Signal Strength Indicator (RSSI) with respect to distance. This work did not employ a web server to disseminate the collected data and the carrier vehicle was not specified. Hsieh et al [20] tracks cars and is targeted for pollution and weather monitoring. The work by Sanchez-Iborra et al [21] is most similar to our work as it also tracks boats. It is desktop oriented compared to our cloud-based system. This makes our system closer to the IoT paradigm. 


\section{CONCLUSION}

We present a LoRa based open source system for tracking vehicles. We successfully built the prototype and proved the correctness of system operation. Future improvements can be done in various aspects. Hardware-wise, the transponder can be miniaturized and then tested in more robust environmental conditions. Software-wise, the scripts should be refactored to ensure better maintainability as the system grows.

\section{ACKNOWLEDGMENTS}

This work is supported by the Ministry of Education and Universiti Teknologi Malaysia (UTM). This work is financially supported by the Transdisciplinary Research Grant Scheme (TRGS) 4L855. The authors would like to thank Langkawi Development Authority (LADA), Koperasi Kilim and the Research Management Center (RMC), UTM for making this research a success.

\section{REFERENCES}

[1] fLi S, Da Xu L, Zhao S. The internet of things: a survey. Information Systems Frontiers. vol. 17(2), pp. 243-59, 2015.

[2] Mekala MS, Viswanathan P. "A Survey: Smart agriculture IoT with cloud computing." 2017 International conference on Microelectronic Devices, Circuits and Systems (ICMDCS), pp. 1-7, 2017.

[3] M. Centenaro, L. Vangelista, A. Zanella and M. Zorzi, "Long-range communications in unlicensed bands: the rising stars in the IoT and smart city scenarios," IEEE Wireless Communications, vol. 23(5), pp. 60-67, 2016.

[4] Laplante PA, Laplante N., "The internet of things in healthcare: Potential applications and challenges," IT Professional. vol. 1(3), pp. 2-4, 2016.

[5] Mohamad, N., M. F. A. Khanan, I. A. Musliman, W. H. W. Kadir, A. Ahmad, M. Z. A. Rahman, M. H. Jamal, M. Zabidi, N. M. Suaib, and R. M. Zain, "Spatio-temporal analysis of river morphological changes and erosion detection using very high resolution satellite image." In IOP Conference Series: Earth and Environmental Science, vol. $169(1), 2018$

[6] Lee S, Tewolde G, Kwon J. "Design and implementation of vehicle tracking system using GPS/GSM/GPRS technology and smartphone application," 2014 IEEE World Forum on Internet of Things (WF-IoT), pp. 353-358, 2014.

[7] Verma G, Verma H, Singh I, Vikram A, Singhal S, Kumar A, Banarwal S, Goel K. "Wireless position tracking of a DTMF based mobile robot using GSM and GPS.” Indian Journal of Science and Technology, vol. 8(17), 2015

[8] Kamble, P. A., \& Vatti, R. A. "Bus tracking and monitoring using RFID." 2017 Fourth International Conference on Image Information Processing (ICIIP), pp. 1-6, 2017.

[9] Kais Mekk, Eddy Bajica, Frederic Chaxela, \& Fernand Meyer, "A comparative study of LPWAN technologies for large-scale IoT deployment”, ICT Express, 2018.

[10] Rashmi Sharan Sinha, Yiqiao Wei, Seung-Hoon Hwang, “A survey on LPWA technology: LoRa and NB-IoT”, ICT Express 3, 2017.

[11] Wang H, Fapojuwo AO. "A survey of enabling technologies of losw power and long-range machine-to-machine communications." IEEE Communications Surveys \& Tutorials, vol. 19(4), pp. 2621-39, 2017.

[12] Baharudin A. M., Yan W. "Long-range wireless sensor networks for geolocation tracking: Design and evaluation." 2016 International Electronics Symposium (IES), IEEE, pp. 76-80, 2016.

[13] San-Um W, Lekbunyasin P, Kodyoo M, Wongsuwan W, Makfak J, Kerdsri J. "A long-range low-power wireless sensor network based on U-LoRa technology for tactical troops tracking systems," Third Asian Conference on Defence Technology (ACDT), pp. 32-35, 2016.

[14] Zinas, N., Kontogiannis, S., Kokkonis, G., Valsamidis, S., \& Kazanidis, I. "Proposed open source architecture for Long Range monitoring. The case study of cattle tracking at Pogoniani," Proceedings of the 21st Pan-Hellenic Conference on Informatics - PCI 2017 pp. 1-6, 2017.

[15] Li L, Ren J, Zhu Q. "On the application of LoRa LPWAN technology in Sailing Monitoring System.” 13th Annual Conference on Wireless On-demand Network Systems and Services (WONS), IEEE, pp. 77-80, 2017.

[16] N.S. Shariff, T.A. Musa, S. Ses, I.A. Musliman \& H.-K. Lee (2015). "Performance analysis of ISKANDARnet: a research-based network RTK positioning system,” Journal of Spatial Science, 60(2), pp. 365-386.

[17] Maksimović M, Vujović V, Davidović N, Milošević V, Perišić B. "Raspberry Pi as Internet of things hardware: performances and constraints," Proceedings of 1st International Conference on Electrical, Electronic and Computing Engineering ICETRAN 2014, Vrnjačka Banja, Serbia, June 2 - 5, 2014.

[18] Coley G. "Beaglebone black system reference manual." Texas Instruments, Dallas, 2013.

[19] Singh KJ, Kapoor DS. "Create Your Own Internet of Things: A survey of IoT platforms," IEEE Consumer Electronics Magazine, vol. 6(2), pp. 57-68, 2017.

[20] Hsieh CL, Ye ZW, Huang CK, Lee YC, Sun CH, Wen TH, Juang JY, Jiang JA. "A vehicle monitoring system based on the LoRa technique," World Academy of Science, Engineering and Technology, International Journal of Mechanical, Aerospace, Industrial, Mechatronic and Manufacturing Engineering, vol. 11(5), pp. 1093-9, 2017.

[21] Sanchez-Iborra R, G Liaño I, Simoes C, Couñago E, Skarmeta A. "Tracking and Monitoring System Based on LoRa Technology for Lightweight Boats,” Electronics, vol. 8(1), pp. 15, 2019. 